\title{
Nitidine chloride inhibits ovarian cancer cell migration and invasion by suppressing MMP-2/9 production via the ERK signaling pathway
}

\author{
XIANGXIU SUN ${ }^{1}$, LIN LIN $^{1}$, YING CHEN ${ }^{1}$, TIANFENG LIU ${ }^{1}$, RONGHUALIU ${ }^{1}$, \\ ZHONGDE WANG ${ }^{2}, \mathrm{KAI} \mathrm{MOU}^{2}, \mathrm{JIAXU}^{2}, \mathrm{BO} \mathrm{LI}^{3}$ and HAIBO SONG ${ }^{2}$ \\ ${ }^{1}$ Department of Gynecology and Obsterics, Linyi People's Hospital, Linyi, Shandong 276000; \\ ${ }^{2}$ Prenatal Diagnosis Center, Zibo Maternal and Child Health Hospital, Zibo, Shandong 255000; \\ ${ }^{3}$ Department of Cardiology, Central Hospital of Zibo, Zibo, Shandong 255036, P.R. China
}

Received March 24, 2015; Accepted January 12, 2016

DOI: $10.3892 / \mathrm{mmr} .2016 .4929$

\begin{abstract}
Nitidine chloride (NC) has been demonstrated to exert anti-tumor effects on various types of tumor. However, no studies have investigated the anti-metastatic effect of $\mathrm{NC}$ on ovarian cancer cells, and the underlying mechanisms have not yet been clearly established. The present study aimed to determine the effect of $\mathrm{NC}$ on the migration and invasion of ovarian cancer cells. Cell viability and proliferation of ovarian cancer cells were assessed by MTT assay. A scratch wound healing assay and Transwell assays were performed to detect migration and invasion of cells, respectively. The expression levels of matrix metalloproteinase (MMP)-2 and 9 were detected at the mRNA and protein level following stimulation with NC. Subsequently, the expression of mitogen-activated protein kinases was detected by western blot analysis. Finally, an inhibitor of extracellular signal-regulated kinase (ERK) was applied to investigate the effect of $\mathrm{NC}$ on the expression of MMP-2/9 as well as the migration and invasion of cells. It was found that $\mathrm{NC}$ suppressed the proliferation, migration and invasion of A2780 ovarian cancer cells. NC downregulated MMP-2 and MMP-9 in a dose- and time-dependent manner. In addition, $\mathrm{NC}$ was also able to downregulate phosphorylation of ERK. Furthermore, by applying an ERK inhibitor, U0126, the effect of NC on the expression of MMP-2/9 and inhibition of cell migration and invasion was verified. Taken together, these results demonstrated that $\mathrm{NC}$ inhibited the migration
\end{abstract}

Correspondence to: Dr Haibo Song, Prenatal Diagnosis Center, Zibo Maternal and Child Health Hospital, 12 Xing Yuan Dong Road, Zibo, Shandong 255000, P.R. China

E-mail: songhb88241@163.com

Dr Bo Li, Department of Cardiology, Central Hospital of Zibo, 54 Gong Qing Tuan Xi Road, Zibo, Shandong 255036, P.R. China

E-mail: libosubmit@163.com

Key words: nitidine chloride, migration, invasion, ovarian cancer cells, extracellular signal-regulated kinase and invasion of ovarian cancer cells via the ERK signaling pathway.

\section{Introduction}

Ovarian cancer is the second most common gynecological malignancy and the fifth most frequent cause of cancer-associated mortality in females worldwide, with $>2$ million new cases and 1 million mortalities in $2013(1,2)$. At present, surgery followed by chemotherapy is the current standard treatment for localized ovarian cancer. However, the highly invasive property and difficulty of detection of early-stage ovarian cancer leads to a poor prognosis (3). As a result, only $40 \%$ of patients in all stages survive and $70-80 \%$ of patients with distant metastases succumb to the disease within 5 years of diagnosis $(4,5)$. Thus, the therapeutic options for metastatic ovarian cancer remain limited. Therefore, there is an urgent need to elucidate the molecular mechanisms and to identify novel agents for ovarian cancer patients to obtain an improved treatment outcome.

Increasing evidence has demonstrated the pivotal role of the extracellular matrix (ECM) and matrix metalloproteinases (MMPs) in cancer invasion and metastasis $(6,7)$. As a family of structurally conserved, zinc-dependent endopeptidases, the MMPs are important in proteolysis of the ECM. Among them, MMP-2/9 can degrade components of the ECM and thus eliminate the barrier that restrains cancer invasion $(8,9)$. Mitogen-activated protein kinase (MAPK) family members, including extracellular signal-regulated kinase (ERK), p38 and c-Jun N-terminal kinase (JNK), have been demonstrated to be crucial in mediating MMP2/9 production $(10,11)$.

In previous years, natural products have obtained increasing attention as new anti-tumor therapeutic drugs due to their relatively few side effects (12). Among them, nitidine chloride (NC; Fig. 1A) is a natural bioactive phytochemical alkaloid derived from the root of Zanthoxylum nitidum (Roxb). Previous studies have demonstrated that NC has anti-inflammatory, anti-oxidant, anti-fungal and anti-HIV functions $(13,14)$. NC has been demonstrated to have anti-tumor activity in different types of cancer. NC can induce apoptosis and inhibit the 
growth and metastasis of renal cancer $(15,16)$. NC was also found to suppress the proliferation of hepatocellular carcinoma (17). Another study demonstrated that $\mathrm{NC}$ is able to inhibit the growth of gastric cancer via the signal transducer and activator of transcription 3 signaling pathway (18). In addition, $\mathrm{NC}$ is able to suppress the growth of breast cancer and inhibit its metastasis through the c-Src/focal adhesion kinase pathway $(19,20)$. However, to the best of our knowledge, no studies have investigated whether NC has a direct effect on ovarian cancer migration and invasion or the mechanisms of this effect.

In the present study, the effects of $\mathrm{NC}$ on ovarian cancer cell migration and invasion, as well as the underlying molecular mechanisms were evaluated.

\section{Materials and methods}

Cell lines and reagents. The human A2780 ovarian cancer cell line was obtained from the American Type Culture Collection (Manassas, VA, USA) and cells were routinely cultured in RPMI-1640 containing 10\% fetal bovine serum (FBS), $100 \mathrm{U} / \mathrm{ml}$ penicillin and $100 \mu \mathrm{g} / \mathrm{ml}$ streptomycin (Macgene Biotechnology Ltd., Beijing, China) in $5 \% \mathrm{CO}_{2}$ at $37^{\circ} \mathrm{C}$. Monoclonal rabbit anti-human ERK1/2 (cat. no. 4695; 1:1,000 dilution), monoclonal rabbit anti-human phospho-ERK1/2 (cat. no. 4370; 1:1,000 dilution), monoclonal rabbit anti-human p38 (cat. no. 8690; 1:1000 dilution), monoclonal rabbit anti-human phospho-p38 (cat. no. 4631; 1:1,000 dilution), monoclonal rabbit anti-human JNK (cat. no. 9252; 1:1,000 dilution), monoclonal rabbit anti-human phospho-JNK (cat. no. 4668; 1:1,000 dilution), monoclonal rabbit anti-human MMP-2 (cat. no. 13132; 1:1,000 dilution) and monoclonal rabbit anti-human MMP-9 (cat. no. 13667; 1:1,000 dilution) antibodies were purchased from Cell Signaling Technology, Inc. (Danvers, MA, USA). NC was purchased from Shanghai Tauto Biotech Co., Ltd. (Shanghai, China) and dissolved in dimethyl sulfoxide (DMSO). U0126, a selective inhibitor of ERK, was purchased from Sigma-Aldrich (St. Louis, MO, USA).

MTT assay of cell viability and proliferation. Cell viability and proliferation were assessed using a 3-(4,5-dimethylthiazol-2-yl)-2,5-diphenyltetrazolium bromide (MTT; Beyotime Institute of Biotechnology, Haimen, China) assay. A2780 cells (5,000 cells/well) in $100 \mu 1$ medium were seeded into 96-well plates. Following stimulation with $\mathrm{NC}$ of various concentrations $(0,1,2.5,5$ and $10 \mu \mathrm{M})$ for various times $(0,6,12,24$ and $48 \mathrm{~h}$ ), $20 \mu 1$ MTT ( $5 \mathrm{mg} / \mathrm{ml}$ ) was added into each well. Following incubation for $4 \mathrm{~h}$ at $37^{\circ} \mathrm{C}, 100 \mu \mathrm{l}$ of DMSO was added to each well for another $15 \mathrm{~min}$. Finally, the absorbance values were determined using a microplate luminometer (iMark; Bio-Rad Laboratories, Inc., Hercules, CA, USA) at $490 \mathrm{~nm}$. A2780 cells stimulated with $0 \mu \mathrm{M} \mathrm{NC}$ at various time points $(0,6,12,24$ and $48 \mathrm{~h})$ were used as the control group.

$R N A$ extraction and reverse transcription-quantitative polymerase chain reaction (RT- $q P C R)$. Total RNA was extracted from A2780 cells using TRIzol reagent (Invitrogen; Thermo Fisher Scientific, Inc., Waltham, MA, USA) and then reverse transcribed to cDNA using a RevertAid First Strand cDNA Synthesis kit (Thermo Fisher Scientific, Inc.) according to the manufacturer's instructions. qPCR analysis was performed using a LightCycler (Bio-Rad Laboratories Inc.). The primer sequences used for qPCR were as follows: MMP-2, forward: 5'-TTGATGGCATCGCTCAGATC-3' and reverse: 5'-TTG TCACGTGGCGTCACAGT-3'; MMP-9, forward: 5'-GAC GCAGACATCGTCATCCA-3' and reverse: 5'-CACAAC TCGTCATCGTCGAAA-3'. The cycling conditions were as follows: $95^{\circ} \mathrm{C}$ for $10 \mathrm{sec}$, followed by 40 cycles of $95^{\circ} \mathrm{C}$ for $5 \mathrm{sec}, 60^{\circ} \mathrm{C}$ for $30 \mathrm{sec}$ and a final extension at $72^{\circ} \mathrm{C}$ for $3 \mathrm{~min}$. SYBR Green I was purchased from Invitrogen (Thermo Fisher Scientific, Inc.) Melting curves were assessed to confirm the specificity of the products generated for each set of primers. Following amplification, the $\Delta \Delta \mathrm{Cq}$ comparative method was then used to normalize the relative levels of gene expression to GAPDH (21). Experiments were performed in triplicate.

Western blot analysis. Following treatment, the cells were harvested and then the protein was extracted using protein lysis buffer (Beyotime Institute of Biotechnology). Centrifugation was performed at $10,000 \mathrm{xg}$ for $15 \mathrm{~min}$ at $4^{\circ} \mathrm{C}$. Total cell protein concentrations were determined using the bicinchoninic acid protein assay kit (Pierce Biotechnology Inc., Rockford, IL, USA). Equal protein from cell lysates was loaded onto 12\% SDS-PAGE gels (Bio-Rad Laboratories, Inc.). Following electrophoresis, proteins were transferred onto polyvinylidene difluoride (PVDF) membranes (Millipore, Billerica, MA, USA) and then blocked with 5\% fat-free milk at room temperature for $1 \mathrm{~h}$, and incubated with the indicated primary antibodies overnight at $4^{\circ} \mathrm{C}$. Subsequently, the membranes were washed with Tris-buffered saline and Tween 20 and incubated with polyclonal goat anti-rabbit horseradish peroxidase-conjugated IgG (cat. no. ZDR-5306; 1:10,000 dilution; ZSGB-BIO, Beijing, China) secondary antibody for $1 \mathrm{~h}$ at room temperature. Immune complexes were detected with enhanced chemiluminescence reagents and the blots were quantified by densitometric analysis using the Alpha Imager 2200 (Alpha Innotech Corp., Santa Clara, CA, USA). Reactions were performed once per PVDF membrane.

Scratch wound healing assay. A scratch wound healing assay was used to assess the migration ability of the A2780 cells. In brief, the A2780 cells (1x10\% $/$ well) were seeded in 6-well plates and cultured with RPMI-1640 supplemented with $10 \%$ FBS. When reaching confluency, each well was scratched with a $200 \mu 1$ pipette tip. To assess the effects of $\mathrm{NC}$ on the migration of A2780 cells, $5 \mu \mathrm{M} \mathrm{NC}$ was added to the plates. After $24 \mathrm{~h}$ of incubation, images of the wound healing areas were captured and then the distance between two cell edges was analyzed by Image J software (version 1.48; National Institutes of Health, Bethesda, MD, USA).

In vitro invasion assay. To evaluate the effect of $\mathrm{NC}$ on the invasive ability of A2780 cells, the transwell system was used. A2780 cells were cultured in Boyden chambers, with $8-\mu \mathrm{m}$ pore filter inserts, in 24-well plates (Corning Life Sciences, Corning, NY, USA). The pore inserts were pre-coated with Matrigel (BD Biosciences, San Jose, CA, USA) overnight. A2780 cells $\left(1 \times 10^{5}\right.$ cells/well) were suspended in $100 \mu \mathrm{l}$ RPMI-1640 supplemented with 1\% FBS and added to the 
A<smiles></smiles>

Nitidine chloride

B

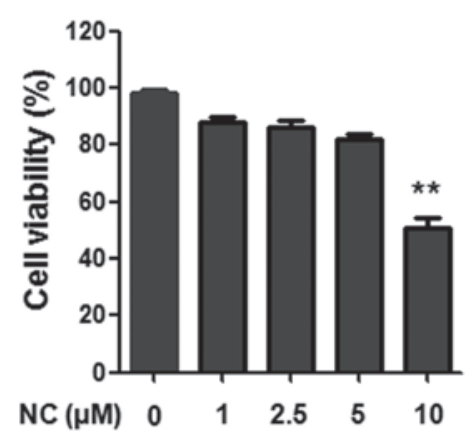

C

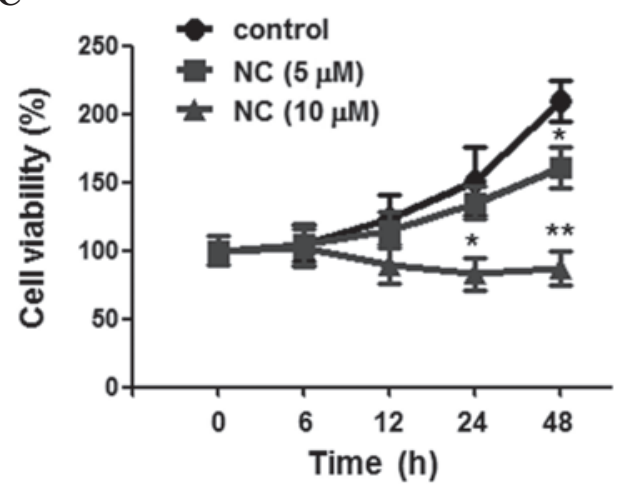

A

NC ( $\mu \mathrm{M}) \quad 0 \quad 5$

$\mathrm{Oh}$
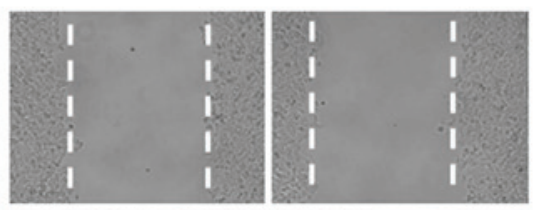

$24 \mathrm{~h}$

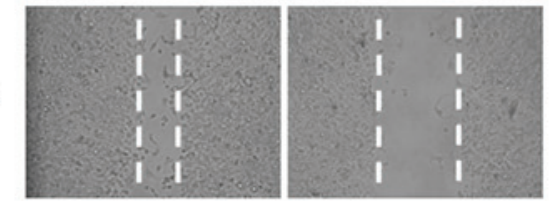

$\dot{*} *$

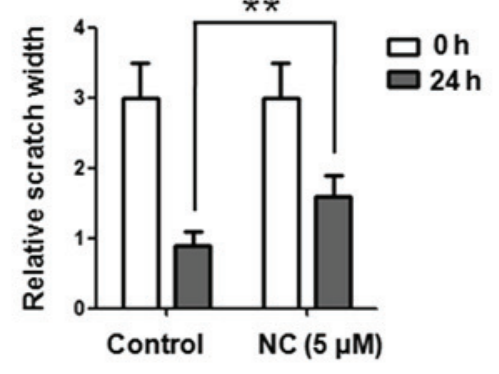

B
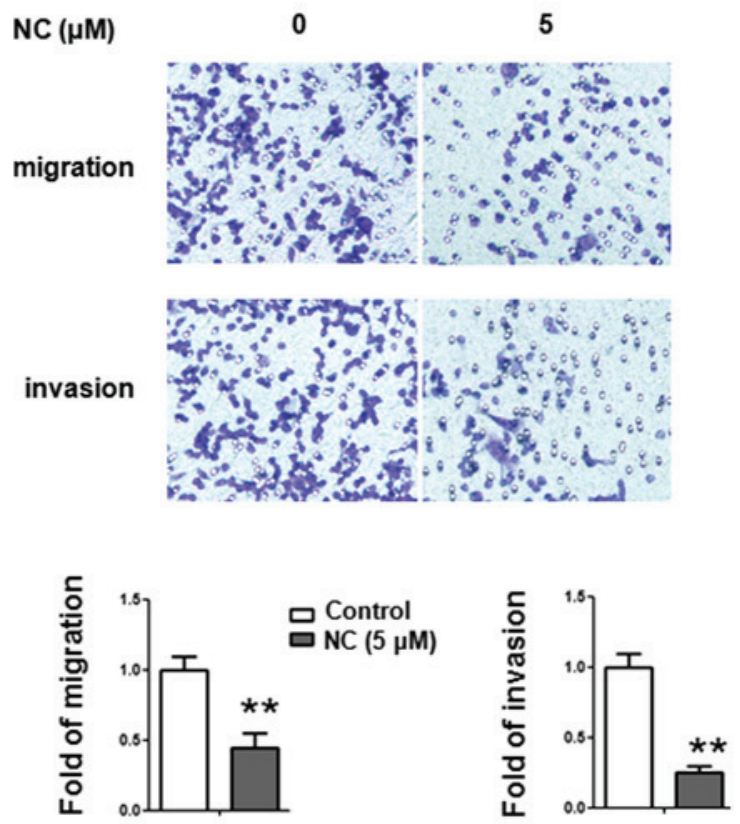

Figure 2. NC inhibits the migration and invasion of A2780 ovarian cancer cells. (A) A2780 cells were treated with $\mathrm{NC}$ at a concentration of $5 \mu \mathrm{M}$ for $24 \mathrm{~h}$ and then assessed by a wound healing assay. (B) A2780 cells were treated with $\mathrm{NC}$ at concentrations of $5 \mu \mathrm{M}$ for $24 \mathrm{~h}$. The effect of $\mathrm{NC}$ on the migration and invasion of A2780 ovarian cancer cells was assessed by a Transwell assay. The bar graph represents the results of three independent experiments. ${ }^{* *} \mathrm{P}<0.01$ vs. the control group. $\mathrm{NC}$, nitidine chloride.

were added to the lower chamber. The cells on the top of the membrane were gently scraped using a swab. After $24 \mathrm{~h}$ of incubation at $37^{\circ} \mathrm{C}$, the cells attaching to the lower surface were fixed with methanol and stained with $0.1 \%$ crystal violet (Beyotime Institute of Biotechnology) for $15 \mathrm{~min}$ at room temperature. A total of five random high-power fields (magnification, x200; Nikon E100; Nikon Corp, Tokyo, Japan) of each sample were selected and counted to evaluate the average number of invasive cells.

In vitro migration assay. For the migration assay, cells were added to upper chambers without coated Matrigel. The assay was performed as described above for the invasion assay. The cells on the lower surface were also counted in five randomly selected fields and then the cell number was analyzed statistically.

Statistical analysis. The data are expressed as the mean \pm standard deviation. All experiments were repeated at least three times. Comparisons among values for all groups were performed by one-way analysis of variance. Holm's t-test was used for analysis of differences between different groups. $\mathrm{P}<0.05$ was considered to indicate a statistically significant difference. 

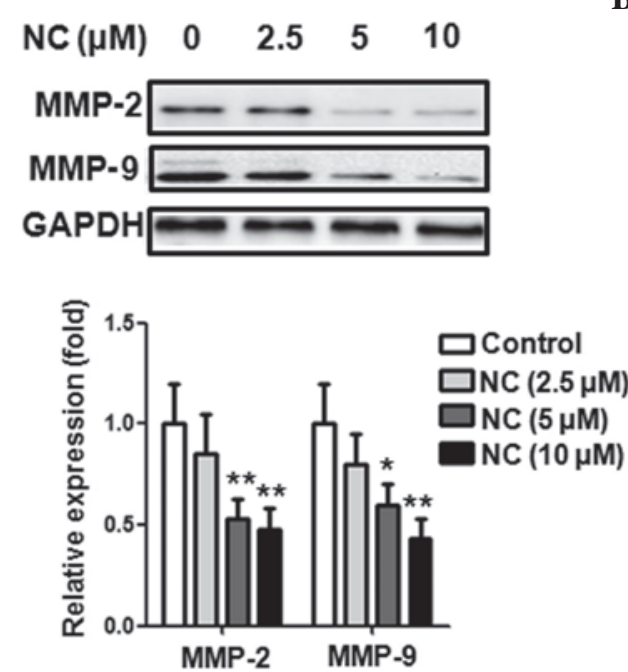

C

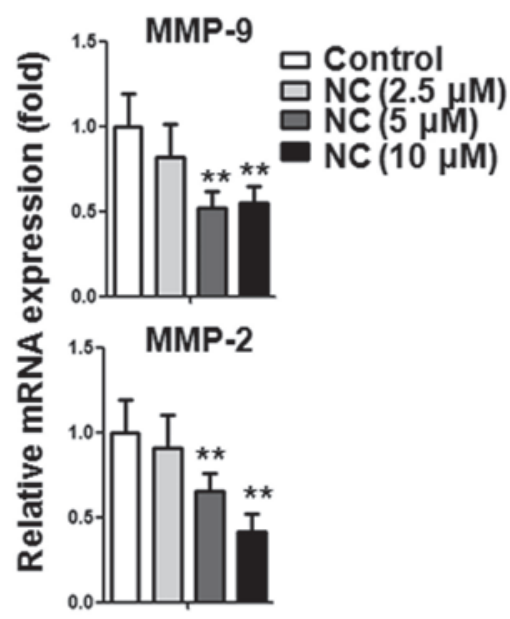

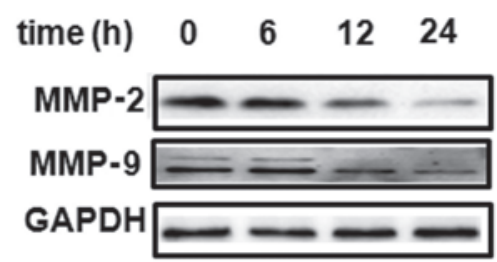

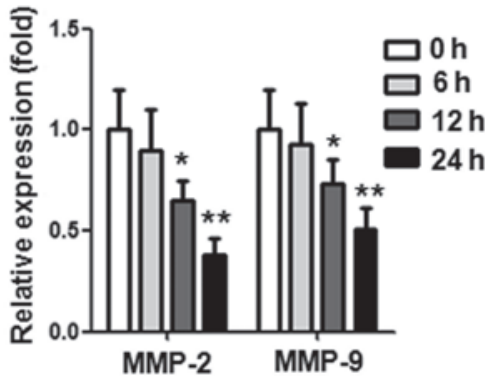

D

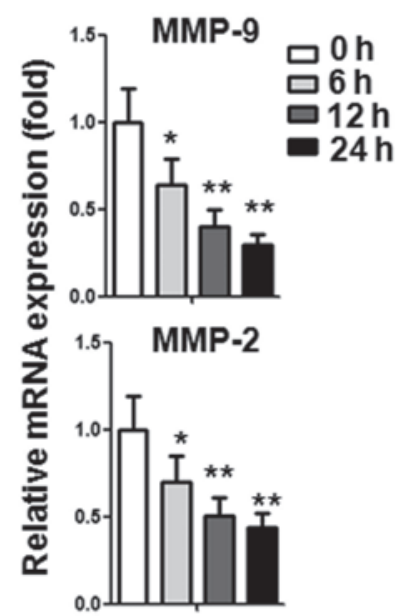

Figure 3. NC decreases the expression of MMP-2 and MMP-9 in A2780 ovarian cancer cells. (A and C) A2780 cells were treated with NC at different concentrations $(0,2.5,5$ and $10 \mu \mathrm{M})$ for $24 \mathrm{~h}$ and the level of MMP-2 and MMP-9 expression was determined by western blot analysis and qPCR. (B and D) A2780 cells were stimulated with $5 \mu \mathrm{M}$ NC for different time periods $(0,6,12$ and $24 \mathrm{~h})$ and the level of MMP-2 and MMP-9 expression was determined by western blot analysis and qPCR. ${ }^{*} \mathrm{P}<0.05$ and ${ }^{* *} \mathrm{P}<0.01 \mathrm{vs}$. the control group. Data are presented as the mean \pm standard deviation from three independent experiments. $\mathrm{NC}$, nitidine chloride; MMP, matrix metalloproteinase; qPCR, quantitative polymerase chain reaction; GAPDH, glyceraldehyde 3-phosphate dehydrogenase.

\section{Results}

NC inhibits the cell viability of ovarian cancer cells. The structure of NC is shown in Fig. 1A. To determine the specific role of NC on the cell viability of A2780 cells, an MTT assay was used as described in Materials and methods. As shown in Fig. $1 \mathrm{~B}$, various concentrations $(0,1,2.5,5$ and $10 \mu \mathrm{M})$ of $\mathrm{NC}$ were added to the cultured A2780 cells. At a dose of $10 \mu \mathrm{M}$, NC significantly inhibited the viability of A2780 cells after $24 \mathrm{~h}$ incubation. However, at concentrations $<10 \mu \mathrm{M}(1,2.5$ and $5 \mu \mathrm{M}$ ), the inhibitory effect was not significant. Furthermore, 5 and $10 \mu \mathrm{M} \mathrm{NC}$ were selected to stimulate the cells at different time points $(0,6,12,24$ and 48 h). As shown in Fig. 1C, after $24 \mathrm{~h}$ stimulation, $\mathrm{NC}$ significantly inhibited the cell viability at a dose of $10 \mu \mathrm{M}$, while $5 \mu \mathrm{M} \mathrm{NC}$ did not significantly inhibit cell viability. However, after $48 \mathrm{~h}$ stimulation, 5 and $10 \mu \mathrm{M}$ $\mathrm{NC}$ significantly inhibited cell viability. As a result, $5 \mu \mathrm{M} \mathrm{NC}$ for $24 \mathrm{~h}$ was selected in the subsequent migration and invasion experiments in order to exclude the effect of cell viability.
$N C$ inhibits the migration and invasion of ovarian cancer cells. The wound healing assay was used to investigate the effect of $\mathrm{NC}$ on the migration of ovarian cancer cells. A2780 ovarian cancer cells were treated with $\mathrm{NC}$ at a concentration of $5 \mu \mathrm{M}$ for $24 \mathrm{~h}$. As shown in Fig. 2A, migration of A2780 cells was inhibited by $\mathrm{NC}(5 \mu \mathrm{M})$. The results of the wound healing assay demonstrated that healing over the scratch was significantly deceased following treatment with NC. In order to further examine the effect of $\mathrm{NC}$ on cell migration and invasion, a Transwell assay was performed. A2780 cells were treated with $\mathrm{NC}$ at a concentration of $5 \mu \mathrm{M}$ for $24 \mathrm{~h}$. As shown in Fig. 2B, the migration and invasion of A2780 cells were significantly inhibited by NC $(5 \mu \mathrm{M})$. The results of the Transwell assay indicated that NC could inhibit the migratory and invasive ability of ovarian cancer cells.

$N C$ downregulates the expression of MMP-2/9 in ovarian cancer cells. Numerous evidence has supported that MMPs, particularly MMP-2 and MMP-9, are important in the process 
A

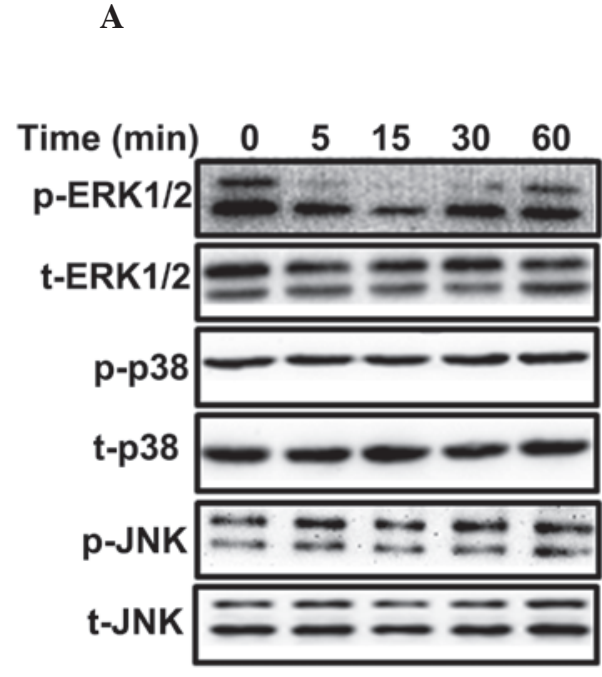

B

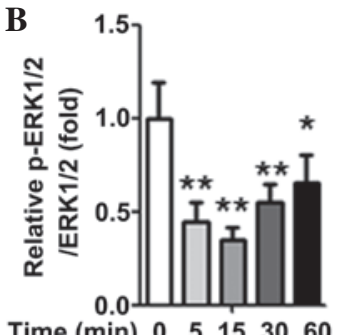

Time (min) $0 \quad 5153060$ Time (min) 055153060
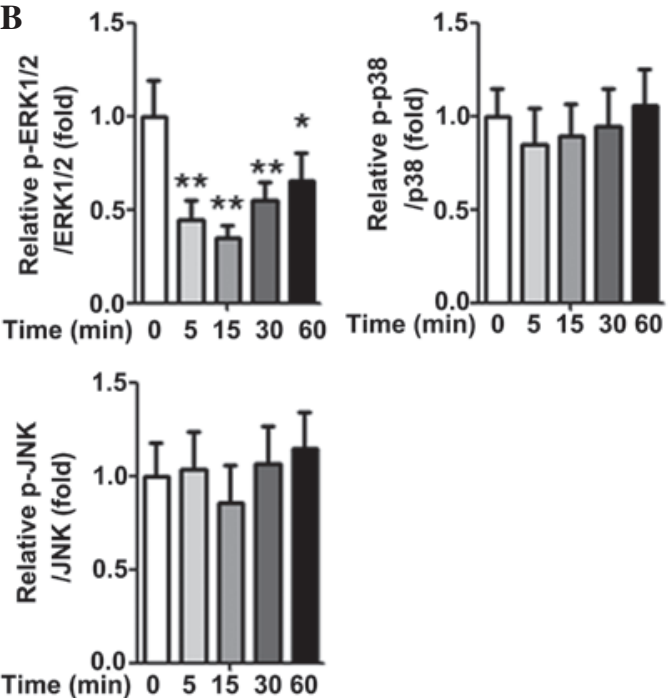

Time (min) 05153060
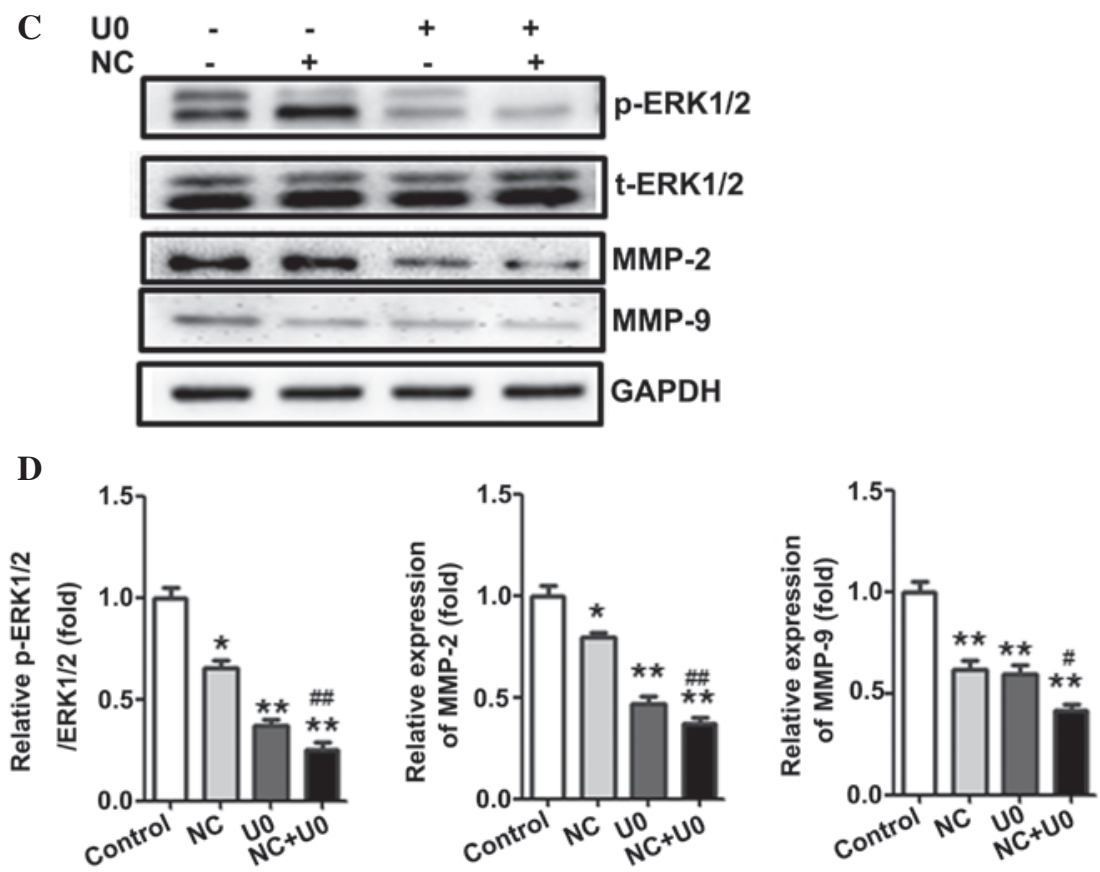

Figure 4. ERK1/2, but not p38 or JNK, regulates NC-mediated production of MMP-2 and MMP-9 in A2780 ovarian cancer cells. (A) A2780 cells were stimulated with $5 \mu \mathrm{M} \mathrm{NC}$ for different time periods $(0,5,15,30$ and $60 \mathrm{~min})$ and the levels of p-ERK1/2, ERK1/2, p-p38, p38, p-JNK and JNK were analyzed by western blotting. (B) Statistical analysis of the western blotting results. ${ }^{*} \mathrm{P}<0.05,{ }^{* *} \mathrm{P}<0.01$ vs. the control group. (C) A2780 cells were treated with NC $(5 \mu \mathrm{M})$ for $24 \mathrm{~h}$ and $\mathrm{U} 0126(10 \mu \mathrm{M})$ was added to A2780 cells $1 \mathrm{~h}$ prior to NC treatment. The levels of p-ERK1/2, ERK1/2, MMP-2 and MMP-9 were analyzed by western blot analysis with GAPDH as a control. (D) Statistical analysis of the western blotting results. ${ }^{*} \mathrm{P}<0.05,{ }^{* *} \mathrm{P}<0.01$ vs. the control group; ${ }^{\#} \mathrm{P}<0.05$, ${ }^{\# \#} \mathrm{P}<0.01$, compared with the cells treated with NC. Data are presented as the mean \pm standard deviation from three independent experiments. NC, nitidine chloride; MMP, matrix metalloproteinase; ERK, extracellular signal-regulated kinase; JNK, c-Jun N-terminal kinase; GAPDH, glyceraldehyde 3-phosphate dehydrogenase; t-, total.

of cancer cell migration and invasion $(22,23)$. The present study thus determined the effect of NC on MMP-2 and MMP-9 expression in A2780 ovarian cancer cells. Various concentrations of $\mathrm{NC}(0,2.5,5$ and $10 \mu \mathrm{M})$ were added to the A2780 cells, respectively, and the cells were then cultured for another 24 h. As shown in Fig. 3A, NC treatment significantly decreased the expression of MMP-2 and MMP-9 in A2780 cells at a concentration of 5 and $10 \mu \mathrm{M}$. The A2780 cells were then stimulated with $5 \mu \mathrm{M} \mathrm{NC}$ for different time periods $(0,6$, 12 and 24 h). As shown in Fig. 3B, following stimulation with $5 \mu \mathrm{M} \mathrm{NC}$ for $6 \mathrm{~h}$, the expression of MMP-2 and MMP-9 was not altered. However, when the stimulating time was extended to 12 and $24 \mathrm{~h}$, the expression of MMP-2 and MMP-9 was significantly decreased compared with the control group. In addition, identical treatments were performed and qPCR was applied to detect the mRNA levels of MMP-2 and MMP-9. As shown in Fig. 3C, the relative mRNA expression of MMP-2 and MMP-9 was significantly decreased when treated with 5 and $10 \mu \mathrm{M}$ NC. Similar to the protein level, it also decreased gradually following stimulation with $5 \mu \mathrm{M}$ for 6,12 and $24 \mathrm{~h}$ (Fig. 3D). The results above suggest that NC inhibited the production of MMP-2 and MMP-9 in a dose- and time-dependent manner at the mRNA and protein levels. The results above also indicate that the inhibitory effect of $\mathrm{NC}$ on A2780 

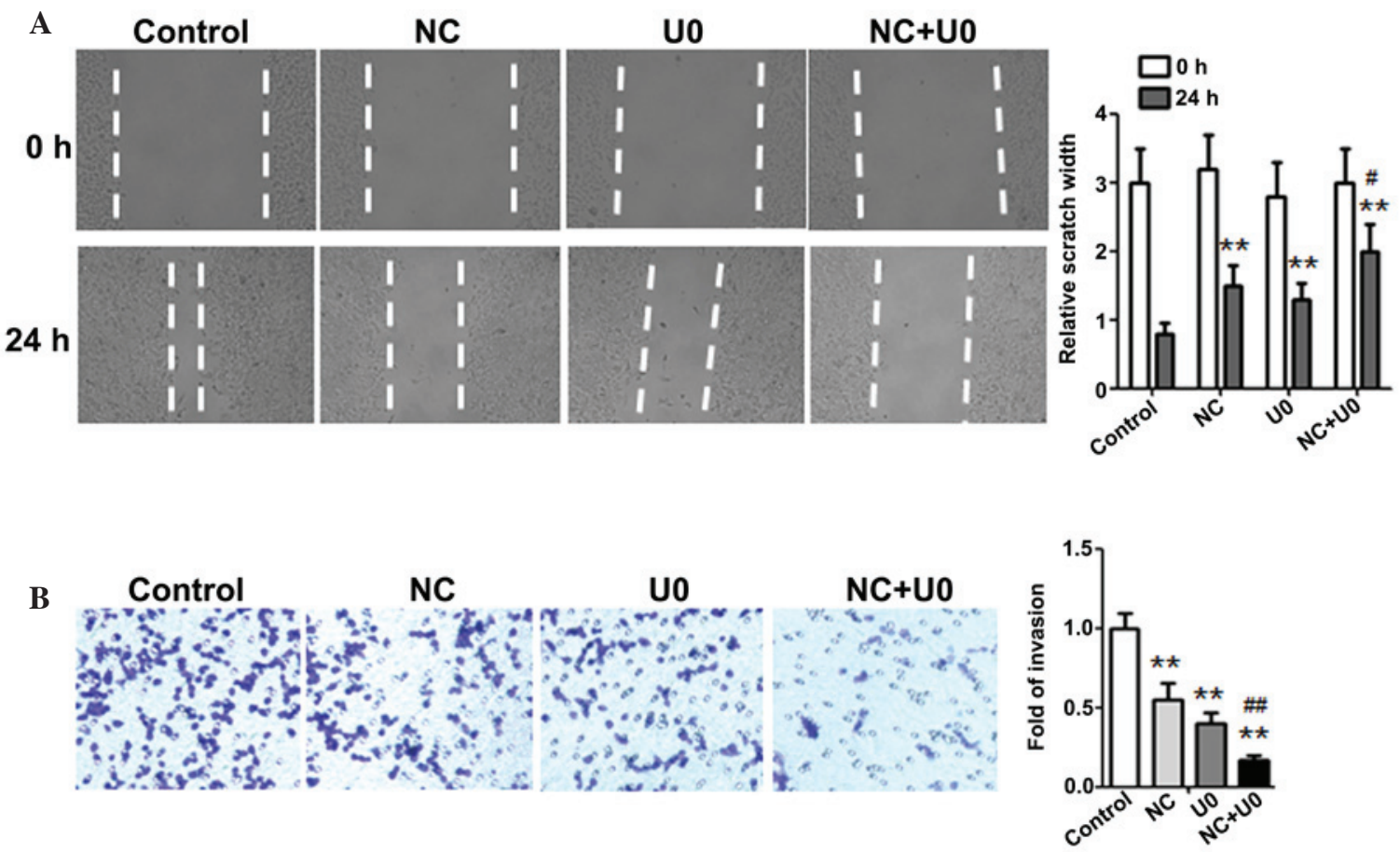

Figure 5. Inhibition of extracellular signal-regulated kinase 1/2 signaling enhances the anti-metastatic effect of NC in A2780 ovarian cancer cells. (A) A2780 cells were treated with NC $(5 \mu \mathrm{M})$ and/or U0126 $(10 \mu \mathrm{M})$ for $24 \mathrm{~h}$, and then assessed by a wound healing assay. (B) A2780 cells were treated with NC (5 $\mu \mathrm{M})$ and/or U0126 $(10 \mu \mathrm{M})$ for $24 \mathrm{~h}$. The effect of NC on the invasion of A2780 ovarian cancer cells was assessed by a Transwell assay. The results are presented as the mean \pm standard deviation from three independent experiments. ${ }^{* *} \mathrm{P}<0.01$ vs. the control group; ${ }^{\#} \mathrm{P}<0.05,{ }^{\# \#} \mathrm{P}<0.01$, compared with the cells treated with NC. NC, nitidine chloride.

cell invasion and migration may be associated with MMP-2 and MMP-9 production.

ERK1/2 signaling pathway mediates inhibition of MMP-2/9 production following treatment with $N C$. The MAPK signaling pathway is important in the development of various types of cancer. Inhibition of MAPK activation has been demonstrated to suppress tumor cell migration and invasion (24). To determine the association between $\mathrm{NC}$ and the production of MMP-2 and MMP-9, the relative expression of three members of the MAPK family, including phospho-JNK, phospho-p38 and phospho-ERK1/2 were investigated following treatment of A2780 cells with $5 \mu \mathrm{M} \mathrm{NC}$ for $0,5,15,30$ and $60 \mathrm{~min}$. As shown in Fig. 4A and B, the relative expression of phospho-ERK1/2 was significantly downregulated compared with the control group. The activity of phospho-ERK1/2 rapidly decreased after 5-30 min stimulation and gradually increased after $1 \mathrm{~h}$ stimulation. However, the expression of phospho-JNK and phospho-p38 was not altered. The results above suggested that the ERK pathway may be involved in MMP-2 and MMP-9 production of ovarian cancer cells.

To further investigate whether the effect of $\mathrm{NC}$ is ERK-dependent, U0126 (ERK inhibitor) was applied to inhibit ERK activation. As shown in Fig. 4C and D, inhibition of ERK activity with U0126 could further downregulate the expression of MMP-2 and MMP-9 compared with NC treatment. These results further demonstrated that NC-inhibited MMP-2 and MMP-9 production may be ERK dependent.

Inhibition of the ERK pathway enhanced the anti-metastatic effect of NC in ovarian cancer cells. To further investigate whether the anti-metastatic effect of $\mathrm{NC}$ was attributed to ERK signaling suppression, the effect of U0126 on A2780 cell migration in the presence or absence of $\mathrm{NC}$ was examined. As shown in Fig. 5A, the results of the wound healing assay demonstrated that the NC-induced inhibition of wound healing was significantly enhanced by using an ERK inhibitor. Similar results were observed using the Transwell assay (Fig. 5B), which also demonstrated that inhibition of ERK activation could significantly enhance the NC-induced inhibition of ovarian cancer cell invasion. These results above support the theory that suppression of metastasis by $\mathrm{NC}$ is regulated by inhibition of MMP-2/9 production though the ERK signaling pathway in ovarian cancer cells.

\section{Discussion}

Metastasis is considered the primary cause of mortality in the majority of cancer patients and is one of the most crucial issues in cancer research. Therefore, it is important to examine the molecular mechanisms of metastasis and to identify effective agents to inhibit cancer metastasis. However, traditional chemotherapeutics are restricted in long-term application due to their toxicity and side effects. There has been increasing attention on natural drugs in tumor therapy with fewer side effects $(25,26)$. Accumulating evidence has demonstrated that $\mathrm{NC}$ possesses the capacity to inhibit the proliferation, migration and invasion and/or induce the apoptosis of breast, renal, gastric and hepatocellular cancer cells (15-20). Although previous studies have revealed the anti-tumor efficacy of $\mathrm{NC}$, whether $\mathrm{NC}$ has any effect on ovarian cancer cell migration and invasion, as 
well as the detailed molecular mechanisms have not been elucidated. The present study initially evaluated the effect of NC on the viability of cultured ovarian cancer cells and the results revealed that $5 \mu \mathrm{M}$ NC significantly inhibited cell proliferation after $48 \mathrm{~h}$ of incubation, while no difference was observed before $24 \mathrm{~h}$. As a result, $24 \mathrm{~h}$ was selected as the stimulation time period and $5 \mu \mathrm{M}$ as the stimulation concentration for the following experiments involving cell migration and invasion, in order to exclude the effect of proliferation. To the best of our knowledge, the present study demonstrated for the first time that NC could effectively inhibit ovarian cancer cell migration and invasion. Furthermore, NC inhibited ovarian cancer cell migration and invasion by suppressing MMP-2 and MMP-9 production via the ERK signaling pathway. The present study provided a novel molecular mechanism explaining how NC exhibits its anti-tumor effect on ovarian cancer cells.

The metastasis and invasion of ovarian cancer is a complicated and multi-step process that is mediated by numerous factors. MMPs are proteinases that are crucial for malignant cells in the proteolytic degradation of the basement membrane and ECM, in order for malignant cells to migrate and invade into surrounding tissues $(22,23)$. Among these, the role of MMP-2 and MMP-9 has been underlined; their type IV collagenase activity is essential during the initial period of metastasis and invasion $(8,9)$. Increased expression of MMP-2 and MMP-9 was associated with a poor prognosis in ovarian cancer patients $(27,28)$. The suppressive role of NC on the migration and invasion of A2780 ovarian cancer cells was then evaluated via scratch wound healing and Transwell assays. Furthermore, the decreased expression of MMP-2 and MMP-9 observed following NC treatment was associated with the inhibition of migration and invasion in A2780 ovarian cancer cells. Therefore, the finding that NC downregulated the expression of MMP-2 and MMP-9, may show a potential association between the inhibition of metastasis by $\mathrm{NC}$ and MMP activity.

Several studies have reported that MAPK family members, including ERK, p38 and JNK, can lead to MMP2/9 production and potentially promote the proliferation and metastasis of tumors $(10,11,29)$. As one of the crucial signal transduction pathways, the ERK signaling pathway is involved in the regulation of proliferation, apoptosis, migration and invasion of cancer cells (30-32). In the present study, the ERK activity in ovarian cancer cells was assessed by western blot analysis. The results demonstrated that the expression of phospho-ERK was downregulated following treatment with NC. To verify that the ERK signaling pathway was involved in the inhibition of ovarian cancer cell migration and invasion by NC, ERK activity was inhibited by applying the ERK inhibitor U0126. It was found that suppression of ERK phosphorylation by U0126 enhanced MMP2/9 downregulation induced by NC. In addition, inhibition of ERK activity further inhibited cell migration and invasion. These results suggested that NC suppressed ovarian cancer cell migration and invasion through inhibiting ERK activity and decreasing the production of MMP-2/9. The results demonstrated that applying the ERK inhibitor U0126 enhanced NC-induced downregulation of MMP-2/9, further demonstrating that ERK was upstream of MMP-2/9.
In conclusion, to the best of our knowledge, the present study indicated for the first time that NC inhibited the migration and invasion of ovarian cancer cells by suppressing MMP-2/9 production. Furthermore, the effect of NC was regulated by the ERK signaling pathway. Therefore, our findings suggested that NC is a possible drug for ovarian cancer therapy. However, further in vivo research is required.

\section{References}

1. Siegel R, Ma J, Zou Z and Jemal A: Cancer statistics, 2014. CA Cancer J Clin 64: 9-29, 2014.

2. Jemal A, Bray F, Center MM, Ferlay J, Ward E and Forman D: Global cancer statistics. CA Cancer J Clin 61: 69-90, 2011.

3. Sun ZL, Tang YJ, Wu WG, Xing J, He YF, Xin DM, Yu YL, Yang Y and Han P: AZD1480 can inhibit the biological behavior of ovarian cancer SKOV3 cells in vitro. Asian Pac J Cancer Prev 14: 4823-4827, 2013

4. Holschneider CH and Berek JS: Ovarian cancer: Epidemiology, biology, and prognostic factors. Semin Surg Oncol 19: 3-10, 2000.

5. Vaughan S, Coward JI, Bast RC Jr, Berchuck A, Berek JS, Brenton JD, Coukos G, Crum CC, Drapkin R, Etemadmoghadam D, et al: Rethinking ovarian cancer: Recommendations for improving outcomes. Nat Rev Cancer 11: 719-725, 2011.

6. Stallings-Mann M and Radisky D: Matrix metalloproteinase-induced malignancy in mammary epithelial cells. Cells Tissues Organs 185: 104-110, 2007.

7. Kessenbrock K, Plaks V and Werb Z: Matrix metalloproteinases: Regulators of the tumor microenvironment. Cell 141: 52-67, 2010.

8. Liotta LA and Stetler-Stevenson WG: Metalloproteinases and cancer invasion. Semin Cancer Biol 1: 99-106, 1990.

9. Himelstein BP, Canete-Soler R, Bernhard EJ, Dilks DW and Muschel RJ: Metalloproteinases in tumor progression: The contribution of MMP-9. Invasion Metastasis 14: 246-258, 1994.

10. Kim BS, Park JY, Kang HJ, Kim HJ and Lee J: Fucoidan/FGF-2 induces angiogenesis through JNK- and p38-mediated activation of AKT/MMP-2 signalling. Biochem Biophys Res Commun 450: 1333-1338, 2014.

11. Jin YJ, Park I, Hong IK, Byun HJ, Choi J, Kim YM and Lee H: Fibronectin and vitronectin induce AP-1-mediated matrix metalloproteinase-9 expression through integrin alpha $\alpha(5) \beta(1) / \alpha(\mathrm{v})$ $\beta(3)$-dependent Akt, ERK and JNK signaling pathways in human umbilical vein endothelial cells. Cell Signal 23: 125-134, 2011.

12. Gordaliza M: Natural products as leads to anticancer drugs. Clin Transl Oncol 9: 767-776, 2007.

13. Wang Z, Jiang W, Zhang Z, Qian M and Du B: Nitidine chloride inhibits LPS-induced inflammatory cytokines production via MAPK and NF-kappab pathway in RAW 264.7 cells. J Ethnopharmacol 144: 145-150, 2012.

14. Del Poeta M, Chen SF, Von Hoff D, Dykstra CC, Wani MC, Manikumar G, Heitman J, Wall ME and Perfect JR: Comparison of in vitro activities of camptothecin and nitidine derivatives against fungal and cancer cells. Antimicrob Agents Chemother 43: 2862-2868, 1999.

15. Fang Z, Tang Y, Jiao W, Xing Z, Guo Z, Wang W, Xu Z and Liu Z: Nitidine chloride induces apoptosis and inhibits tumor cell proliferation via suppressing ERK signaling pathway in renal cancer. Food Chem Toxicol 66: 210-216, 2014.

16. Fang Z, Tang Y, Jiao W, Xing Z, Guo Z, Wang W, Shi B, Xu Z and Liu Z: Nitidine chloride inhibits renal cancer cell metastasis via suppressing AKT signaling pathway. Food Chem Toxicol 60: 246-251, 2013.

17. Liao J, Xu T, Zheng JX, Lin JM, Cai QY, Yu DB and Peng J: Nitidine chloride inhibits hepatocellular carcinoma cell growth in vivo through the suppression of the JAK1/STAT3 signaling pathway. Int J Mol Med 32: 79-84, 2013.

18. Chen J, Wang J, Lin L, He L, Wu Y, Zhang L, Yi Z, Chen Y, Pang $X$ and Liu M: Inhibition of STAT3 signaling pathway by nitidine chloride suppressed the angiogenesis and growth of human gastric cancer. Mol Cancer Ther 11: 277-287, 2012.

19. Pan X, Han H, Wang L, Yang L, Li R, Li Z, Liu J, Zhao Q, Qian M, Liu M and Du B: Nitidine Chloride inhibits breast cancer cells migration and invasion by suppressing c-Src/FAK associated signaling pathway. Cancer Lett 313: 181-191, 2011. 
20. Sun M, Zhang N, Wang X, Cai C, Cun J, Li Y, Lv S and Yang Q: Nitidine chloride induces apoptosis, cell cycle arrest, and synergistic cytotoxicity with doxorubicin in breast cancer cells. Tumour Biol 35: 10201-10212, 2014.

21. Zhang Y,Li R, Meng Y, Li S, Donelan W, Zhao Y, Qi L, Zhang M, Wang X, Cui T, Yang LJ, et al: Irisin stimulates browning of white adipocytes through mitogen-activated protein kinase p38 MAP kinase and ERK MAP kinase signaling. Diabetes 63 514-525, 2014

22. Gialeli C, Theocharis AD and Karamanos NK: Roles of matrix metalloproteinases in cancer progression and their pharmacological targeting. FEBS J 278: 16-27, 2011.

23. Kallakury BV, Karikehalli S, Haholu A, Sheehan CE, Azumi N and Ross JS: Increased expression of matrix metalloproteinases 2 and 9 and tissue inhibitors of metalloproteinases 1 and 2 correlate with poor prognostic variables in renal cell carcinoma. Clin Cancer Res 7: 3113-3119, 2001

24. Rajoria S, Suriano R, Wilson YL, Schantz SP, Moscatello A, Geliebter J and Tiwari RK: 3,3'-diindolylmethane inhibits migration and invasion of human cancer cells through combined suppression of ERK and AKT pathways. Oncol Rep 25: 491-497, 2011.

25. Surh YJ: Cancer chemoprevention with dietary phytochemicals. Nat Rev Cancer 3: 768-780, 2003.
26. Thomasset SC, Berry DP, Garcea G, Marczylo T, Steward WP and Gescher AJ: Dietary polyphenolic phytochemicals-promising cancer chemopreventive agents in humans? A review of their clinical properties. Int J Cancer 120: 451-458, 2007.

27. Li LN, Zhou X, Gu Y and Yan J: Prognostic value of MMP-9 in ovarian cancer: A meta-analysis. Asian Pac J Cancer Prev 14: 4107-4113, 2013.

28. FuZ, Xu S,Xu Y,Ma J,Li J and Xu P: The expression of tumor-derived and stromal-derived matrix metalloproteinase 2 predicted prognosis of ovarian cancer. Int J Gynecol Cancer 25: 356-362, 2015.

29. Thompson $\mathrm{N}$ and Lyons $\mathrm{J}$ : Recent progress in targeting the Raf/MEK/ERK pathway with inhibitors in cancer drug discovery. Curr Opin Pharmacol 5: 350-356, 2005.

30. Gendron S, Couture J and Aoudjit F: Integrin alpha2beta1 inhibits Fas-mediated apoptosis in T lymphocytes by protein phosphatase 2A-dependent activation of the MAPK/ERK pathway. J Biol Chem 278: 48633-48643, 2003.

31. Shelton JG, Steelman LS, White ER and McCubrey JA: Synergy between PI3K/Akt and Raf/MEK/ERK pathways in IGF-1R mediated cell cycle progression and prevention of apoptosis in hematopoietic cells. Cell Cycle 3: 372-379, 2004.

32. Ono $\mathrm{H}, \mathrm{Basson} \mathrm{MD}$ and Ito $\mathrm{H}$ : PTK6 promotes cancer migration and invasion in pancreatic cancer cells dependent on ERK signaling. PloS One 9: e96060, 2014. 